\title{
Missing Historical Perspectives in our Current Teaching of Biochemistry
}

It is with considerable interest that I read the recent kind letter from INSA President to INSA fellows about the desirability of giving due importance to scholars who work in the area of history of science. I have often observed lately while teaching undergraduate classes, this is the age when hysteria has become far more important than history, so the move initiated by INSA is commendable.

In this article, I would like to dwell on how various textbooks of biochemistry have been widely adopted in India over the years. Recently, in an article in Proceedings of the Indian National Science Academy, I referred to the fact that at least in India, the "flavour of the era" book often dictates framing of new syllabi. So, as the "adopted" book changed, so did what we all teach in our courses. Increasingly, I observed that not only our undergraduate students but even postgraduate students are becoming allergic to references being given to multiple books. So, it has to be one book for each course preferably.

This historical account is prompted by a recent exchange which I had with one of my very bright younger colleagues. In an informal discussion, I asked, "Which one he thought was the first textbook of biochemistry?" I was not aware that I had thrown a googly. After some hesitation, he said Lehninger (Lehninger's biochemistry)!

In some ways, much of the early biochemistry evolved out of physiology. So, there were some books on physiological chemistry. Perhaps the first recognized textbook of biochemistry was General Biochemistry by Joseph S. Fruton and Sofia Simmonds (Yale University) published in 1953. That textbook described in details the experiments which led to the discovery of metabolic pathways for glucose, fat and amino acids. As Fruton was an enzymologist, the chapters on proteins and enzymes recorded excellent historical account of those early days.
Biochemistry at one time was also given the fashionable status of a multidisciplinary science. In Fruton's book, one sees early participation with organic chemists helping with isolation and characterization of biological molecules. The next generation textbooks were by White and Handler and by West and Todd; all these books are still available although the new editions have additional authors. Both were written from the perspectives of teaching biochemistry in Medical Schools. It is interesting that nutrition, hormones, detoxification as separate chapters (which were there in these books) have disappeared from the books which appeared later. Some of these are repackaged differently. Can we again have all our vitamins at one place please! In the current books, they receive cursory treatment and are scattered all over. Both Streyer's and Lehninger's books treat hormones under signal transduction. Somehow, one misses the perspectives. Streyer does not believe in teaching you the concept of negative and positive nitrogen balance. Today's students miss out on the brilliant studies by Rose on the discovery of amino acids. One gets a feeling that if it does not involve rDNA based tools or use of expensive tools, it is not worth teaching. That may be fine for students in Europe or USA. Is it good for us in India?

However, let me come back to a book which is still considered a great favourite with my contemporaries. Basic Biological Chemistry by Mahler and Cordes constituted a paradigm shift in many ways. It brought the "chemistry" part of biochemistry back in focus. It is the first book wherein reaction mechanisms of many metabolic reactions were given! The chapters on protein structure and enzymology in the book are still the best available in any textbook. Around the same time, a smaller book called outlines of biochemistry was written by Conn and Stumpf. The early editions were the best introductions to biochemistry ever written. The later editions lost as these try to emulate the "Maruti 800 trying to be a limousine" philosophy. 
Lehninger's book has excellent treatment of metabolism, which is not surprising given Lehninger's original contributions in the area. Streyer co-opted people who used to draw figures for scientific American articles! If a book can make a teacher redundant, Streyer's comes close to it! However, it is not a complete textbook. Both these are more recent books and represent biochemistry as we know it. Lehninger's book can be frustrating to read at times. Different aspects of the same story have been segregated and placed far apart.

There have been others, which somehow never became that popular. Rawn's latest edition is good. Zubay's book is not bad. Some people like the book by Voet, Voet and Pratt. If somebody would rather look at metabolism from an organic chemists' perspective, the book by Abeles, Frey and Jencks is the one.

The other day while researching something on cell-cell co-operation in immune systems, I found Janeway [Immunobiology by Charles Janeway] referring to Gnotobiotics - I was actually taught that in my graduate school!

Many years back, I was having lunch with a person (he is an eminent scientist now and it is not necessary to name him) who had done Ph.D. at Imperial College, London with a very renowned scientist. I referred to tomatoes and lightly said lycopene is good for us. He asked, "What is lycopene?" I said, Umm... you know carotenoids?
He was curious and enquired what carotenoids were. Incidentally, his enzymology training is better than mine. So, let us not get too bullish about our training. The point is, we need to retain what is good with our courses. We need to improve on it. We do not need to be weathercocks, so vulnerable to winds of change from the West. We surely need to retain historical perspectives. They teach us how it happened to be discovered. Often brilliant discoveries were made because fantastic tools were not available yet!

By doing away with teaching of historical perspective, we are also deleting teaching what innovation is all about.

So, it is good that we should recognize the value of the area of history of science. Can we please also bring back (a little!) something which we used to teach: scientific thinking, scientific ethics and scientific methods? That would not just help Make in India, it will also help in the making of India (a still better place).

\section{Munishwar Nath Gupta} Emeritus Professor Department of Biochemical Engineering and Biotechnology IIT Delhi 